Provided for non-commercial research and education use. Not for reproduction, distribution or commercial use.

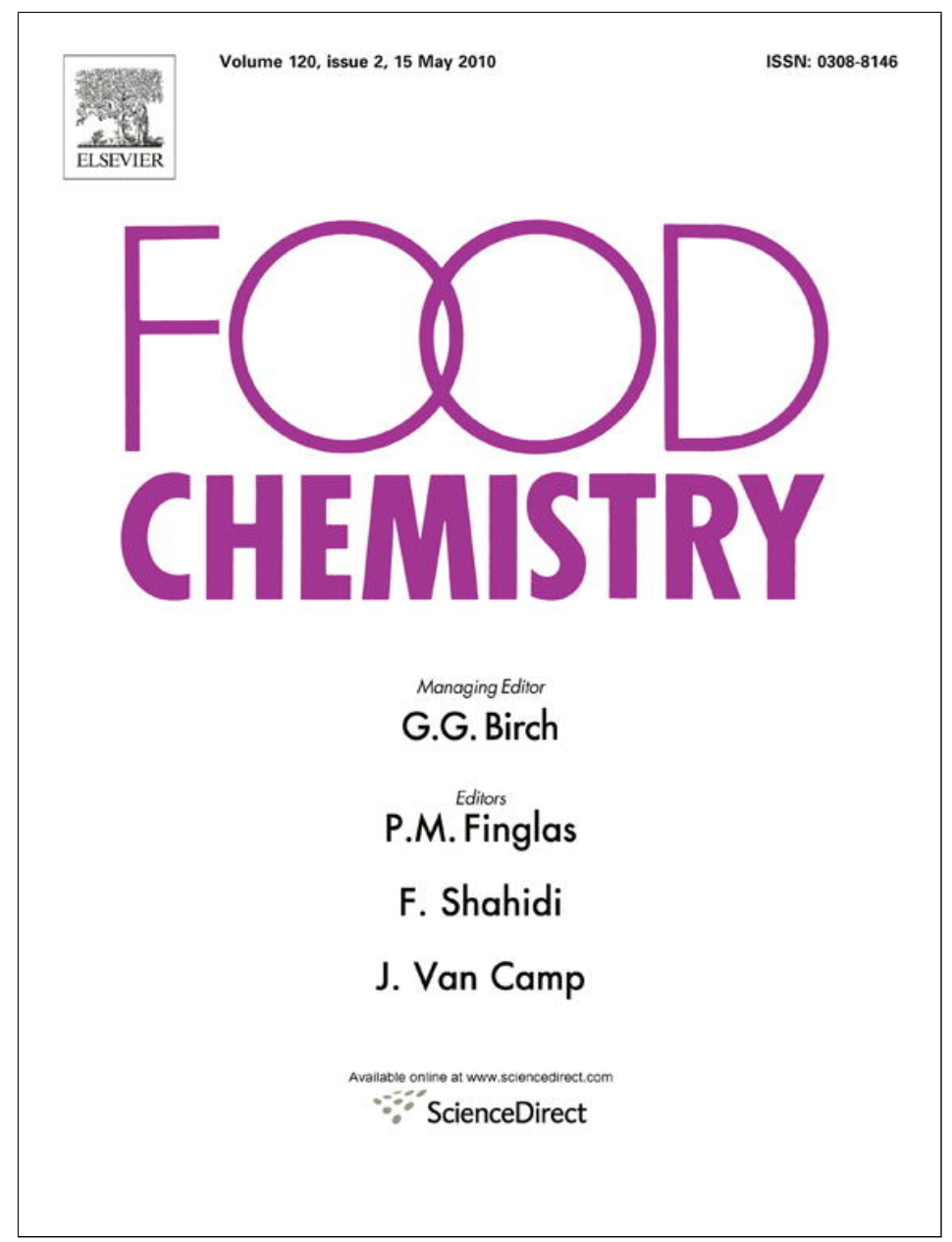

This article appeared in a journal published by Elsevier. The attached copy is furnished to the author for internal non-commercial research and education use, including for instruction at the authors institution and sharing with colleagues.

Other uses, including reproduction and distribution, or selling or licensing copies, or posting to personal, institutional or third party websites are prohibited.

In most cases authors are permitted to post their version of the article (e.g. in Word or Tex form) to their personal website or institutional repository. Authors requiring further information regarding Elsevier's archiving and manuscript policies are encouraged to visit:

http://www.elsevier.com/copyright 


\title{
The impact of the protein network on the pasting and cooking properties of dry pasta products
}

\author{
Charlotte Bruneel *, Bram Pareyt, Kristof Brijs, Jan A. Delcour \\ Laboratory of Food Chemistry and Biochemistry and Leuven Food Science and Nutrition Research Centre (LFoRCe), Katholieke Universiteit Leuven, Kasteelpark \\ Arenberg 20, 3001 Leuven, Belgium
}

\section{A R T I C L E I N F O}

\section{Article history:}

Received 9 June 2009

Received in revised form 11 August 2009

Accepted 21 September 2009

\section{Keywords:}

Commercial pasta

SDS extractable protein

Protein network

Pasta cooking quality

Swelling behaviour

\begin{abstract}
A B S T R A C T
Durum wheat semolina gluten and starch as well as processing conditions determine pasta cooking quality. This study investigated whether, for good organoleptic properties, a permanent protein network needs to be formed during pasta drying or can still be formed during cooking. The cooking quality of 16 spaghetti samples was related to the levels of sodium dodecyl sulphate extractable protein (SDSEP), starch gelatinisation temperatures as well as to the swelling properties of milled dry spaghettis. SDSEP levels in dry and cooked products varied between $31 \%$ and $56 \%$, and $12 \%$ to $21 \%$ of total protein contents, respectively. The highest quality spaghettis had relatively higher levels of SDSEP in the dry product, low starch gelatinisation temperatures and swelling powers, and rigid particles. The lowest quality spaghettis had lower levels of SDSEP and higher gelatinisation temperatures. This work implies that high pasta quality results from an optimal degree of protein polymerisation during drying and/or the subsequent cooking.
\end{abstract}

(c) 2009 Elsevier Ltd. All rights reserved.

\section{Introduction}

Pasta is consumed in large quantities throughout the world. Scientific research has been undertaken to understand the parameters influencing pasta processing and the final product quality. Ideally, cooked pasta is of al dente quality. It is firm and resilient with no surface stickiness and little if any cooking losses (Dexter, Matsuo, \& Macgregor, 1985; Sissons, Ames, Hare, \& Clarke, 2005; Troccoli, Borrelli, De Vita, Fares, \& Di Fonzo, 2000; Wood, Batey, Hare, \& Sissons, 2001). When one considers the durum wheat semolina based dry pasta production process and the subsequent cooking before final consumption, the choice of raw material and processing variables in the production of dry pasta are the only measures one can take to ensure the above cited al dente quality characteristics. In the choice of raw materials, the semolina particle size distribution, the protein content and quality, and the starch properties (level of damaged starch and swelling power) are important quality determining parameters (Cubadda, Carcea, Marconi, \& Trivisonno, 2007; D'Egidio, Mariani, Nardi, Novaro, \& Cubadda, 1990; Delcour, Vansteelandt, Hythier, \& Abécassis, 2000a; Delcour et al., 2000b;

Abbreviations: cP, centiPoise; dm, dry matter; DSC, differential scanning calorimetry; DTT, dithiothreitol; HT, high temperature; RVA, Rapid Visco Analyzer; SDSEP, sodium dodecyl sulphate extractable protein; SE-HPLC, size-exclusion high performance liquid chromatography; SP, swelling power.

* Corresponding author. Tel.: +32 (0) 16321634; fax: +32 (0) 16321997.

E-mail address: charlotte.bruneel@biw.kuleuven.be (C. Bruneel).
Dexter, Matsuo, \& Morgan, 1983; Grant, Dick, \& Shelton, 1993; Oak et al., 2006).

In the first stage of the production process following durum wheat milling, semolina is hydrated and transformed into dough particles which are extruded to generate continuous dough strands that are then dried. As a result of both mixing and extruding, starch granules are entrapped in an amorphous protein matrix (Dexter, Dronzek, \& Matsuo, 1978; Resmini \& Pagani, 1983). Although the main constituent of pasta by far is granular starch, at this stage of the process, it has no network forming ability (Cornell, 2004). The limited portion of damaged starch contains both amylose and amylopectin which takes up high levels of water and can form a transient network based on entanglement (Morrison, Tester, \& Gidley, 1994). However, it is questionable whether damaged starch would be a major factor responsible for the network in dried pasta strands as pasta can also be made in the absence of such starch (Delcour et al., 2000a, 2000b).

This brings us to the network forming ability of gluten. Before drying at elevated temperatures, the glutenin component is (already) well suited to have formed networks in the extruded dough. These networks are transient as they arise from entanglement of the glutenin subunit based polymers as well as from dynamic thiol-disulfide exchange reactions (Veraverbeke \& Delcour, 2002). It is hard to envisage that, at this stage of the process, the other gluten component, i.e. gliadin, would contribute to the network to any significant degree as it is of globular nature. Gliadin, however, determines the viscous properties of the gluten network. 
In the industry, drying cycles involving controlled high temperature (HT) technology have been introduced into pasta production (Pollini, 1996; Zweifel, Handschin, Escher, \& Conde-Petit, 2003). Fairly HT (above $60^{\circ} \mathrm{C}$ ) and relative humidities (between $74 \%$ and $90 \%$ ) can be applied at either the start of the drying phase with high product moisture (HM) (ca. 30\%), or during the final stages of the drying phase at low product moisture (LM) (below 15\%) (Resmini \& Pagani, 1983; Zweifel et al., 2003). There are indications that HT-LM drying may be more effective in ensuring high firmness and low stickiness of cooked pasta (Baiano \& Del Nobile, 2006; Dexter, Matsuo, \& Morgan, 1981; Dexter et al., 1983; Zweifel et al., 2003). Elevated temperatures may cause protein disulfide cross-linking by oxidation of glutenin free sulfhydryl groups (Lagrain, Brijs, Veraverbeke, \& Delcour, 2005; Lagrain, Thewissen, Brijs, \& Delcour, 2008) leading to large protein polymers (Lamacchia et al., 2007). Under well specified conditions, i.e. temperatures exceeding $90{ }^{\circ} \mathrm{C}$ in a model system, glutenin links to gliadin through a sulfhydryl-disulfide exchange mechanism (Lagrain et al., 2008). Thus, it is reasonable to assume that, during HT drying, the proteins polymerise into a (partial) protein network in the raw/uncooked product, and that, under these specified conditions, the protein level would be more important than its quality in obtaining high quality pasta (D'Egidio et al., 1990; Novaro, D’Egidio, Mariani, \& Nardi, 1993). Protein polymerisation as a result of drying can be monitored by measuring the contents of protein extractable in dilute sodium dodecyl sulphate (SDS) solution, i.e. SDSEP (Lagrain et al., 2005). The level of protein unextractable in such medium is then a measure for the degree of protein polymerisation.

During cooking, physical competition between starch swelling and properties of polymerised and polymerising proteins determines whether the final cooked pasta is firm and elastic (when a strong protein network is formed and starch particles are entrapped in this network) or rather sticky and soft (in the opposite case of significant starch swelling) (Delcour et al., 2000a, 2000b; Resmini \& Pagani, 1983). From the above, it is clear that, during HT-LM drying, the continuous protein network, needed for a good cooking quality, is already formed in the raw pasta. This reduces and prevents the negative impact of starch swelling during cooking (Resmini \& Pagani, 1983). In high quality pasta, this network remains continuous during cooking. According to Delcour et al. (2000a), its coherence is dictated by the way it withstands starch swelling. Starch swelling can indeed destroy the protein network during cooking. Substitution of semolina starch with waxy starch from different sources resulted in increased starch swelling properties, and a soft textured pasta (Gianibelli, Sissons, \& Batey, 2005). Hence, the gluten component of pasta as well as its starch properties and processing conditions (especially the drying conditions) are of utmost importance for product quality. However, at present, apart from a pasta cooking test itself, there is no (predictive) analytical tool available which predicts pasta quality. Also, it is unclear whether the protein network needs to be formed already during industrial dry pasta production or can still be formed during the subsequent cooking step. In addition, little is known about the properties of this protein network and its effect on pasta quality.

Against this background, the cooking quality of 16 different commercial dry pasta products was determined and linked to the properties of starch (i.e. swelling) and proteins (i.e. network formation) during production and/or cooking of pasta. The study also used analytical approaches to determine the starch and protein properties which earlier on were used to unravel the impact of rice parboiling on the protein and starch components (Derycke et al., 2005). The swelling properties of ground uncooked pasta products were investigated using swelling power (SP) test and Rapid Visco Analyzer (RVA) heat-moisture-shear treatment. The impact of the protein component on the swelling power and rheological behav- iour was estimated using a reducing agent. Furthermore, the levels of SDSEP in the uncooked and cooked pastas were determined. To the best of our knowledge, such work has, until now, not been reported in the literature.

\section{Materials and methods}

\subsection{Materials}

A set of 16 different dry spaghetti samples manufactured in Europe were purchased in a Belgian supermarket. In this study, five commercial non-heat treated durum wheat semolina samples served as control to have a good overall indication of the properties of the raw material that is used for pasta production. The diameter of all spaghettis was measured with a digital caliper. The mean diameter of each spaghetti sample was calculated from four measurements.

\subsection{Chemicals and reagents}

All used chemicals and reagents were at least of analytical grade and purchased from Sigma-Aldrich (Steinheim, Germany), unless specified otherwise.

\subsection{Composition of semolina and uncooked pasta products}

\subsubsection{Analysis of moisture, starch and protein contents}

All dry spaghettis were ground in a universal mill (IKA Labortechnik, Staufen, Germany) and sieved $(<400 \mu \mathrm{m})$. Moisture contents were determined according to AACC Method 44-19 (AACC, 1983). Starch contents were estimated by gas-liquid chromatography of sorbitol acetate following starch hydrolysis, glucose reduction and derivatisation as described by Englyst and Cummings (1984) and was calculated as 0.9 times the glucose content. Starch damage was determined according to AACC Method 76-31. Protein contents were determined using the Dumas combustion method, an adaptation of the AOAC Official Method (AOAC, 1995) to an automated Dumas protein analysis system (EAS vario Max N/CN, Elt, Gouda, The Netherlands), using 5.7 as the conversion factor. Chemical analyses were performed in triplicate and the results are expressed on a dry matter $(\mathrm{dm})$ basis.

\subsubsection{Differential scanning calorimetry}

Differential scanning calorimetry (DSC) was used to determine the starch gelatinisation characteristics of uncooked ground pasta. It was performed with a DSC Q1000 (TA Instruments, New Castle, DE, USA). Milled spaghetti (ca. $5 \mathrm{mg} \mathrm{dm}$ ) was accurately weighed into an aluminium sample pan and water was added $(1: 2 \mathrm{w} /$ $\mathrm{w} \mathrm{dm} /$ water). The sample pan and an empty reference pan were hermetically sealed and heated from $0{ }^{\circ} \mathrm{C}$ to $140^{\circ} \mathrm{C}$ at $4.0^{\circ} \mathrm{C} / \mathrm{min}$. Calibration was with indium and tin. The starch gelatinisation peak temperature $\left(\mathrm{T}_{\mathrm{p}},{ }^{\circ} \mathrm{C}\right)$ of uncooked pasta samples was determined with TA Q Series Advantage Universal Analyses software (TA Instruments, New Castle, DE, USA). Semolina samples served as control. Results were reported as averages of at least three measurements.

\subsection{Size-exclusion high performance liquid chromatography}

Size-exclusion high performance liquid chromatography (SEHPLC) was conducted using a Shimadzu LC-2010 system (Kyoto, Japan) with automatic injection. The milled dry and cooked spaghetti samples (corresponding to $1.0 \mathrm{mg} \mathrm{dm}$ proteins) were extracted with $1.0 \mathrm{ml}$ sodium phosphate buffer $(50 \mathrm{mM}, \mathrm{pH} 6.8)$ containing $2.0 \%(\mathrm{w} / \mathrm{v})$ SDS (Acros Organics, Geel, Belgium) as well as with 
$1.0 \mathrm{ml}$ of the same buffer containing $2.0 \% \mathrm{w} / \mathrm{v}$ SDS, $1.0 \% \mathrm{w} / \mathrm{v}$ dithiothreitol (DTT, Acros Organics, Geel, Belgium) and 2.0 M urea (Lagrain et al., 2005). The protein extracts were filtered through a $0.45 \mu \mathrm{m}$ membrane (regenerated cellulose; Alltech Associates, Deerfield, MA, USA) and loaded ( $60 \mu \mathrm{l})$ on a Biosep-SEC-S4000 column (Phenomenex, Torrance, CA, USA). The elution solvent was acetonitrile/water $(1: 1, \mathrm{v} / \mathrm{v})$ containing $0.05 \%(\mathrm{v} / \mathrm{v})$ trifluoroacetic acid. Chromatography conditions included: flow rate $1.0 \mathrm{ml} / \mathrm{min}$ and temperature $30^{\circ} \mathrm{C}$ (Veraverbeke, Larroque, Bekes, \& Delcour, 2000), with protein detection at $214 \mathrm{~nm}$. The elution profiles were divided into two fractions using the lowest absorbance reading between the two peaks as the cut-off point. Based on Lagrain et al. (2005), the first peak corresponds to the SDS extractable glutenin, while the second peak was assigned to the SDS extractable gliadin. Total SDSEP levels were calculated from the sum of the peak areas, and expressed as percentage of the peak area of total proteins extracted with the same phosphate buffer containing the above specified levels of SDS, DTT and urea.

In addition, semolina and spaghettis 1 and 16 were extracted before and after cooking with $2.0 \%(\mathrm{w} / \mathrm{v})$ SDS containing sodium phosphate buffer $(50 \mathrm{mM}, \mathrm{pH} 6.8)$ in the presence of different levels of DTT $(0 \% \mathrm{w} / \mathrm{v}, 0.01 \%, 0.1 \%, 0.5 \%, 1.0 \%)$. The levels of proteins extractable in the different buffers were expressed as percentage of the peak areas of proteins extracted with 2.0\% SDS sodium phosphate buffer ( $50 \mathrm{mM}, \mathrm{pH} 6.8$ ) in the presence of $1.0 \%$ DTT and $2.0 \mathrm{M}$ urea.

\subsection{Cooking properties and spaghetti quality}

\subsubsection{Determination of optimal cooking time}

Pasta products $(25 \mathrm{~g})$, broken to a length of $7 \mathrm{~cm}$, were cooked in deionised water $(400 \mathrm{ml})$. The optimal cooking time (al dente point) was that needed to gelatinise starch at the centre of spaghetti strands. It was visually determined by pressing such strands between two plastic plates at different times and measuring the time for the starchy white core of the pasta to disappear (Abécassis, Abbou, Chaurand, Morel, \& Vernoux, 1994; Zweifel et al., 2003).

\subsubsection{Cooking losses}

Pasta products ( $25 \mathrm{~g}$ ), broken to a length of $7 \mathrm{~cm}$, were cooked in deionised water $(400 \mathrm{ml})$ to optimal cooking time. To stop the cooking process, al dente cooked strands were immediately cooled in deionised water. Cooking and rinsing water were recovered quantitatively. The material leached to the cooking water was determined by weighing the freeze-dried cooking and rinsing water. Determination of cooking losses of the pasta products was reproducible as verified by three individual measurements for spaghetti 16 with a standard deviation (expressed in \%) not exceeding $3.5 \%$.

\subsubsection{Water absorption of strands}

Water absorption $\mathrm{g} / \mathrm{g} \mathrm{dm}$ was calculated by relating the weight increase between dry and cooked pasta to the dry matter content of dry pasta with correction for the cooking losses. Determination of water absorption of the pasta products was reproducible as verified by three individual measurements for spaghetti 16 with a standard deviation (expressed in \%) not exceeding $1.5 \%$.

\subsubsection{Texture analysis}

The texture of cooked spaghetti was determined using a TAXT2i Texture Analyzer (Stable Micro Systems, Surrey, UK) using a $25 \mathrm{~mm}$ diameter flat-ended cylindrical probe ( $\mathrm{P} / 25$, Stable Micro Systems). A single spaghetti strand was compressed $50 \%$ at a speed of $1.0 \mathrm{~mm} / \mathrm{s}$. At least nine subsequent compressions of a fresh strand from the same cook followed at $45 \mathrm{~s}$ intervals. The force at $50 \%$ compression was taken as a measure for the firmness $(\mathrm{N})$ of the spaghetti strands. The probe was then moved to its original position with the same speed. The negative peak value, originating from the force needed to remove the probe from the strand, was taken as a measure for the stickiness $(\mathrm{mN})$ of the spaghetti strands. Evidently, thicker pasta requires more force to cut through the strands due to the greater cross-sectional area through which the knife must pass (Wood et al., 2001). To compare the texture of the different pastas, the firmness and stickiness were divided by the radius of the strands. This corresponds to the force by length unit at 50\% compression (Dris \& Niskanen, 1999).

\subsection{Swelling properties}

\subsubsection{Swelling power}

In order to determine the SP, i.e. the swelling power or the weight occupied by $1.0 \mathrm{~g} \mathrm{dm}$ milled spaghetti after gelatinisation in excess water or buffer, a suspension $(1.0 \% \mathrm{w} / \mathrm{v})$ of milled spaghetti in TRIS- $\mathrm{HCl}$ buffer $(100 \mathrm{mM}, \mathrm{pH} 7.0)$ was heated at $100{ }^{\circ} \mathrm{C}$ (30 min) and centrifuged (15 min, 1500g). The sediment was weighed and the SP $(\mathrm{g} / \mathrm{g})$ was calculated. The impact of proteins on SP and leaching behaviour was studied by including the reducing agent DTT $(0.15 \%)$ into the buffer. The total carbohydrate contents of the supernatants were determined using the phenolsulphuric acid method (Dubois, Gilles, Hamilton, Rebers, \& Smith, 1956). All SP determinations were performed at least in triplicate.

\subsubsection{Rapid Visco Analysis}

Milled spaghetti pasting properties were determined with a Rapid Visco Analyzer (RVA-4D, Perten Instruments, Huddinge, Sweden) interfaced with a computer equipped with Thermocline software. Suspensions of dry milled spaghettis $(12.0 \% \mathrm{w} / \mathrm{v} \mathrm{dm}$, total weight is $25.0 \mathrm{~g})$ and TRIS- $\mathrm{HCl}$ buffer $(100 \mathrm{mM}, \mathrm{pH} 7.0)$ were mixed in a RVA canister. The impact of proteins on RVA viscosity was studied by including the reducing agent DTT $(0.15 \%)$ in the buffer. The temperature profile $(31 \mathrm{~min})$ included a temperature holding step $\left(1 \mathrm{~min}\right.$ at $\left.50^{\circ} \mathrm{C}\right)$, a linear temperature increase to $95^{\circ} \mathrm{C}$ at $7.5^{\circ} \mathrm{C} / \mathrm{min}$, a holding step $\left(8 \mathrm{~min}\right.$ at $\left.95^{\circ} \mathrm{C}\right)$, a linear temperature decrease to $50^{\circ} \mathrm{C}$ at $7.5^{\circ} \mathrm{C} / \mathrm{min}$, and a final isothermal step at $50{ }^{\circ} \mathrm{C}(10 \mathrm{~min})$. The paddle speed was $960 \mathrm{rpm}$ for the first $7 \mathrm{~s}$ (homogenisation of the sample) and then $160 \mathrm{rpm}$. The following parameters (Batey, 2007) were determined: pasting temperature $\left({ }^{\circ} \mathrm{C}\right)$, i.e. temperature at which the viscosity first rises above the baseline during the initial heating phase; peak viscosity (centiPoise, $\mathrm{cP}$ ), i.e. the maximum viscosity during the cycle and a measure for shear resistance of particles; and end viscosity (cP), i.e. the viscosity at the end of the run ( $31 \mathrm{~min}$ ). The RVA runs were reproducible as verified by three individual measurements with standard deviations (expressed in \%) of the pasting temperature, peak and end viscosities of $0.7 \%, 1.1 \%$ and $0.4 \%$ respectively.

\subsection{Statistical analysis}

Statistical analyses were conducted using the Statistical Analysis System software 9.2 (SAS Institute, Cary, NC, USA). Tukey's Studentised Range tests were carried out and determined (significance level $P<0.05$ ).

\section{Results and discussion}

3.1. Relation between the composition, gelatinisation temperature, SDSEP levels of semolina and spaghettis, and pasta cooking quality

The starch and protein contents of the semolina and spaghetti samples ranged from $68.9 \%$ to $76.2 \%$, and from $11.7 \%$ to $14.7 \%$, respectively (Table 1 ). Spaghettis 1,2 and 12 had the highest pro- 
tein contents $(13.8 \%, 13.7 \%$ and $14.1 \%$ respectively). The levels of damaged starch of the semolina samples $(4.2-7.1 \%)$ were lower than those of the dry spaghettis $(6.8-10.0 \%)$. During pasta production (mixing and extruding), starch granules are damaged due to mechanical stresses (Lintas \& D’Appolonia, 1973; Vansteelandt \& Delcour, 1998). The most striking difference between the raw material (semolina) and the produced spaghettis was the level of SDSEP. While, typically, $80-85 \%$ of total semolina proteins was SDS extractable, spaghettis had much lower corresponding values (between $31 \%$ and $56 \%$ of total proteins). The results indicate that proteins became less extractable in the SDS medium, and presumably more polymerised, during pasta processing. There was also a striking difference between the level of SDSEP within the spaghettis (between $31 \%$ and $56 \%$ ), and especially between spaghettis 1,2 (55.8\% and 55.0\% respectively) and 15,16 (32.3\% and $31.2 \%$ respectively). In all likelihood, the differences in SDSEP contents between the spaghettis are related to differences in processing conditions. Lower levels of SDSEP may be attributed to more protein polymerisation (Lagrain et al., 2005) in the dry product caused by elevated drying temperatures (Lamacchia et al., 2007; Zweifel et al., 2003). Spaghettis 1 and 2 were most likely dried under gentle conditions, while spaghettis 15 and 16 were presumably dried under severe conditions. The other spaghettis were presumably dried under mild conditions. These assumptions are supported by the fact that the increasing DSC peak gelatinisation temperature went hand in hand with the decreasing content of $\operatorname{SDSEP}\left(R^{2}=0.84\right)$ as presented in Table 1 . Spaghettis 15 and 16 indeed showed the highest peak gelatinisation temperatures. Drying of pasta under severe conditions induces a loss of order of starch during the beginning of the drying cycle followed by an increase of polymer order during the high temperature phase (Zweifel, Conde-Petit, \& Escher, 2000), which leads to an increase of starch gelatinisation temperature (Cunin, Handschin, Walther, \& Escher, 1995; D'Egidio, Mariani, Nardi, \& Novaro, 1993; Yue, Rayas-Duarte, \& Elias, 1999). In addition, using a pilot-scale process, Petitot et al. (2009) showed that $70 \%$ of the proteins of pastas dried at low temperatures $\left(55^{\circ} \mathrm{C}\right)$ was extractable in $1.0 \%(\mathrm{w} / \mathrm{v})$ SDS, while $28 \%$ SDSEP was obtained when drying at very high temperatures $\left(90^{\circ} \mathrm{C}\right)$. From these results, it is tempting to deduce that spaghettis 1 and 2, with relatively

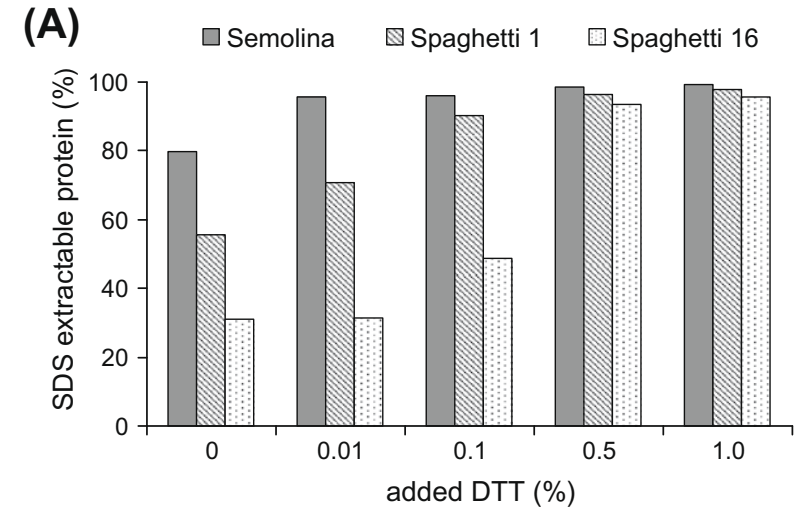

(B)

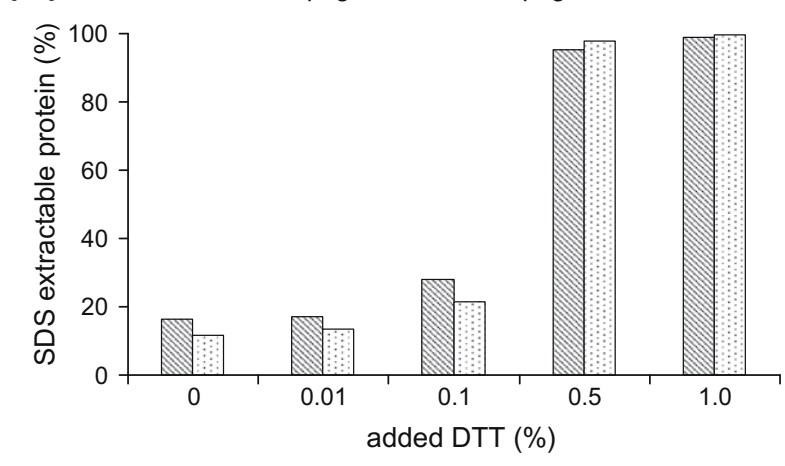

Fig. 1. The effect of different concentrations of dithiothreitol (DTT) on spaghetti SDS extractable protein (EP) levels before (A) and after (B) cooking.

higher SDSEP levels, were probably dried under gentle conditions, while spaghettis 15 and 16, with relatively lower SDSEP levels, were most likely dried under severe conditions.

To determine the differences in protein network formation of the spaghettis, the levels of SDSEP were compared for the semolina samples, dry (uncooked), and cooked spaghettis (Table 1). Ca. 80-

Table 1

Partial composition $(\% \mathrm{dm})$ and gelatinisation temperature of semolina samples and spaghettis.

\begin{tabular}{|c|c|c|c|c|c|c|}
\hline & \multirow[t]{2}{*}{ Starch (\%) } & \multirow[t]{2}{*}{$\operatorname{Tp}^{\mathrm{A}}\left({ }^{\circ} \mathrm{C}\right)$} & \multirow[t]{2}{*}{ Damaged starch (\%) } & \multicolumn{3}{|c|}{ Proteins (\%) } \\
\hline & & & & Total & SDSEP $^{\mathrm{B}}$ in dry product & SDSEP $^{\mathrm{B}}$ in cooked product \\
\hline Semolina 1 & $75.2 \mathrm{a}$ & $60.6 f g$ & 6.9def & $13.5 \mathrm{efg}$ & $84.8 \mathrm{a}$ & - \\
\hline Semolina 2 & $74.1 \mathrm{a}$ & $59.8 \mathrm{~h}$ & $5.6 f g$ & $14.4 \mathrm{~b}$ & $84.2 \mathrm{a}$ & - \\
\hline Semolina 3 & $71.1 \mathrm{a}$ & 61.4cdef & $6.4 \mathrm{ef}$ & $14.7 \mathrm{a}$ & $79.9 a$ & - \\
\hline Semolina 4 & $68.9 a$ & 60.9defg & $4.2 \mathrm{~g}$ & $14.2 \mathrm{~b}$ & $79.6 a$ & - \\
\hline Semolina 5 & $75.2 \mathrm{a}$ & $60.1 \mathrm{gh}$ & 7.1def & $13.3 f g$ & $79.1 \mathrm{a}$ & - \\
\hline Spaghetti 1 & $75.7 \mathrm{a}$ & $60.2 \mathrm{gh}$ & $6.8 \mathrm{def}$ & $13.8 \mathrm{~cd}$ & $55.8 \mathrm{~b}$ & $16.8 \mathrm{e}$ \\
\hline Spaghetti 2 & $73.5 a$ & $60.4 \mathrm{gh}$ & $6.8 \mathrm{def}$ & $13.7 \mathrm{de}$ & $51.0 \mathrm{~b}$ & $14.9 \mathrm{~g}$ \\
\hline Spaghetti 3 & $71.4 a$ & 60.7 efg & 7.7bcdef & $12.8 \mathrm{ijk}$ & $46.2 \mathrm{~cd}$ & $20.8 \mathrm{a}$ \\
\hline Spaghetti 4 & $76.2 \mathrm{a}$ & $61.4 \mathrm{~cd}$ & $9.7 \mathrm{ab}$ & $12.5 \mathrm{k}$ & 43.0de & $16.6 \mathrm{e}$ \\
\hline Spaghetti 5 & $69.1 \mathrm{a}$ & 61.0defg & $8.7 \mathrm{abcd}$ & $12.7 \mathrm{jk}$ & $42.7 \mathrm{de}$ & $20.3 b$ \\
\hline Spaghetti 6 & $74.7 \mathrm{a}$ & $61.4 \mathrm{cde}$ & 7.6bcdef & $13.5 \mathrm{ef}$ & $42.5 \mathrm{de}$ & $19.5 c$ \\
\hline Spaghetti 7 & $73.6 a$ & 61.3cdef & 8.5abcde & 13.0hij & 40.6ef & $16.9 \mathrm{e}$ \\
\hline Spaghetti 8 & $74.1 \mathrm{a}$ & $61.9 c$ & 8.3abcde & $13.7 \mathrm{de}$ & $40.6 \mathrm{ef}$ & $20.8 \mathrm{a}$ \\
\hline Spaghetti 9 & $71.7 \mathrm{a}$ & $62.0 \mathrm{bc}$ & 8.4abcde & $12.6 \mathrm{k}$ & $40.3 \mathrm{ef}$ & $15.5 \mathrm{f}$ \\
\hline Spaghetti 10 & $75.5 a$ & $61.8 \mathrm{c}$ & $10.0 \mathrm{a}$ & 13.1ghi & 40.2efg & $12.4 \mathrm{i}$ \\
\hline Spaghetti 11 & $72.0 \mathrm{a}$ & $62.0 \mathrm{bc}$ & 8.1abcde & $13.8 \mathrm{~cd}$ & $39.4 \mathrm{efg}$ & $15.9 f$ \\
\hline Spaghetti 12 & $74.7 \mathrm{a}$ & $62.6 a b$ & 7.1cdef & $14.1 \mathrm{bc}$ & $36.9 \mathrm{fgh}$ & $17.7 d$ \\
\hline Spaghetti 13 & $75.8 \mathrm{a}$ & $61.8 \mathrm{c}$ & $9.9 \mathrm{abc}$ & 11.71 & 36.5fghi & $18.0 \mathrm{~d}$ \\
\hline Spaghetti 14 & $70.3 a$ & $61.7 \mathrm{c}$ & 6.8def & 13.5def & 34.9ghi & $14.0 \mathrm{~h}$ \\
\hline Spaghetti 15 & $73.4 a$ & $62.8 \mathrm{a}$ & $9.7 \mathrm{ab}$ & $13.2 \mathrm{fgh}$ & 32.3hi & $20.5 a b$ \\
\hline Spaghetti 16 & $71.7 \mathrm{a}$ & $62.7 a b$ & 8.7abcd & $12.8 \mathrm{ijk}$ & $31.2 \mathrm{i}$ & $14.4 \mathrm{~h}$ \\
\hline
\end{tabular}

Values with the same letter within the same column are not significantly different $(P<0.05)$.

A Tp: gelatinisation temperature.

в SDSEP: sodium dodecyl sulphate extractable protein. 
$85 \%$ of total semolina proteins was extractable in the SDS containing medium. As a result of pasta drying, proteins became less extractable, and, most likely, more polymerised. This was most pronounced for spaghettis 15 and 16. Variations in the SDSEP levels after cooking of the spaghettis were less pronounced (12.4$20.8 \%$ ). This indicates that protein polymerisation of spaghettis 1 and 2 occurred mostly during cooking, whereas, significant polymerisation had already occurred by the end of the drying process of the other spaghettis, and especially of spaghettis 15 and 16 . As a result, the protein networks of spaghettis 1, 2 and 15, 16 were significantly different from each other. In the following text, a more in-depth comparison of these four samples is given.

Addition of increasing concentrations of DTT ( $0 \%, 0.01 \%, 0.1 \%$, $0.5 \%$ and $1.0 \% \mathrm{w} / \mathrm{v}$ ) to the SDS containing buffer used for extraction of dry (uncooked) spaghetti 1, led to more extractable protein (Fig. 1A). For spaghetti 16, much more DTT had to be added to the medium to extract the same levels of protein than for spaghetti 1. Thus, it seems that the rate at which proteins of uncooked (dry) spaghetti 16 became more extractable is slower than that of spaghetti 1 . When the SE-HPLC profiles of extracts of dry (uncooked) and cooked spaghettis 1 and 16 (Fig. 2) with increasing concentrations of DTT were compared with the profile of durum wheat semolina extract as control, in the profiles of all samples with $0 \%$ DTT (Fig. 2), the first peak (retention time of $5.8 \mathrm{~min}$ ) contained glutenin aggregates of very high molecular weight, while the second peak (retention time of $9 \mathrm{~min}$ ) consisted of gliadin. The area in be- tween represented glutenin of low molecular weight (Schofield, Bottomley, Timms, \& Booth, 1983). Increasing concentrations of DTT depolymerised the high molecular weight protein material leading to enrichment of the gliadin peak in low molecular weight glutenin subunits. These profiles indicate that the proteins of spaghetti 16 polymerised more during processing, because high DTT concentrations were necessary to increase the protein extractability. In contrast, the profiles for unprocessed semolina and uncooked spaghetti 1 were quite similar. However, for spaghetti 1 still much more DTT was needed to obtain the same levels of SDSEP as for the unprocessed semolina. In addition, the profiles of spaghetti 16 before and after cooking were similar (Figs. 1B and 2), which showed that the spaghetti sample did not undergo much additional polymerisation during cooking. This was in contrast to what could be observed in the profiles of spaghetti 1 (Figs. 1B and 2). Evidently, protein polymerisation in spaghetti 1 but also in spaghetti 2, which showed comparable behaviour, occurred mostly during cooking. In the other samples, significant polymerisation had already occurred during processing. In conclusion, dry spaghettis 1 and 2 had low levels of polymerised protein (ca. 50\% SDSEP in contrast to ca. 80\% SDSEP in semolina), whereas dry spaghettis 15 and 16 had high levels of polymerised protein (ca. 30\% SDSEP) and, hence, were dried under more severe conditions.

Pasta quality (Table 2) is expressed in terms of water absorption, leached material during cooking, and the texture properties firmness and stickiness. The texture of cooked pasta is generally
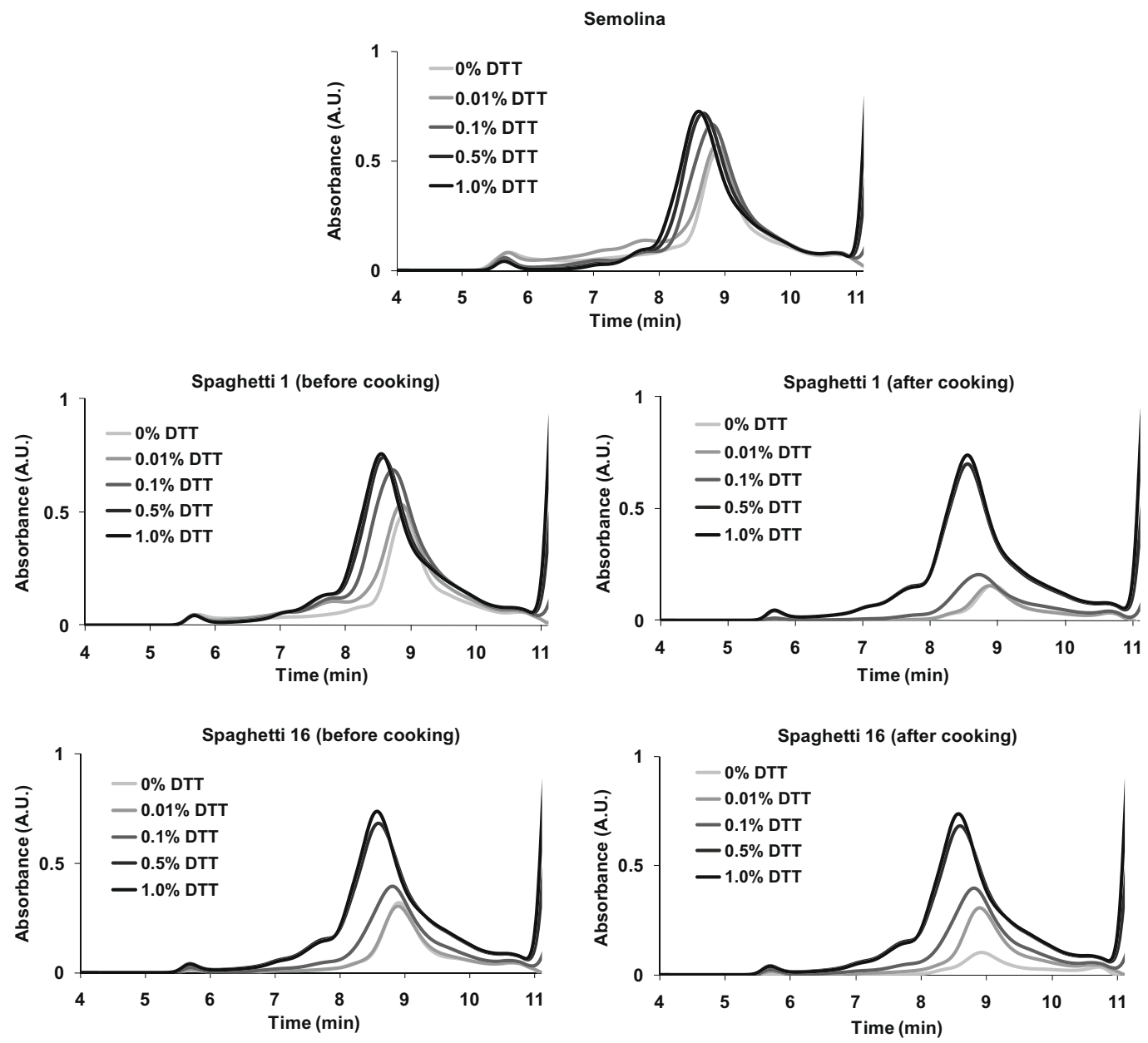

Fig. 2. SE-HPLC profiles indicating the effect of different concentrations of dithiothreitol (DTT) on the SDSEP levels of spaghettis 1 and 16 before and after cooking. Semolina served as control. The peak of purified gliadin [received from $70 \%$ ethanol (v/v) extraction of commercial gluten] dissolved in $2.0 \%$ (w/v) SDS sodium phosphate buffer ( $50 \mathrm{mM}$, $\mathrm{pH}$ 6.8) eluted at 9 min (result not shown). 
recognised as its most important quality aspect. A high cooking quality can be defined as the result of high water absorption, low cooking losses, and good texture (high firmness and low stickiness). Spaghettis 1 and 2 had the highest cooking quality, while spaghettis 15 and 16 had the lowest quality among all spaghettis. In general, it has been reported that HT drying improves cooking properties, as revealed by lower cooking losses, increased firmness and lower surface stickiness (Resmini \& Pagani, 1983; Zweifel et al., 2003). According to Zweifel et al. (2003) and Lamacchia et al. (2007), HT drying at low moisture conditions, during the late stage of the drying process, polymerises proteins into a protein network which entraps the starch granules. This network may restrict water absorption, thus preventing starch leaching and therefore decreasing stickiness. In this study, spaghettis 1 and 2 indeed absorbed more water during cooking than did the samples 15 and 16 (Table 2). However, spaghettis 15 and 16, dried under severe conditions, showed higher cooking losses and stickiness values than spaghettis 1 and 2, dried under gentle conditions (Table 2).

Table 2

Pasta cooking quality related data of 16 commercial spaghettis.

\begin{tabular}{|c|c|c|c|c|}
\hline & $\begin{array}{l}\text { Water absorption } \\
(\mathrm{g} / \mathrm{g} \mathrm{dm})\end{array}$ & $\begin{array}{l}\text { Leached } \\
\text { material during } \\
\text { cooking (\%) }\end{array}$ & $\begin{array}{l}\text { Firmness } \\
(\mathrm{N} / \mathrm{mm})\end{array}$ & $\begin{array}{l}\text { Stickiness } \\
(\mathrm{mN} / \mathrm{mm})\end{array}$ \\
\hline Spaghetti 1 & 2.01 & 4.4 & $7.2 \mathrm{bcd}$ & $0.2 \mathrm{~h}$ \\
\hline Spaghetti 2 & 2.04 & 4.6 & $6.8 \mathrm{def}$ & $4.2 \mathrm{~h}$ \\
\hline Spaghetti 3 & 2.13 & 5.7 & $6.4 \mathrm{fg}$ & 46.3cde \\
\hline Spaghetti 4 & 2.00 & 4.7 & $6.1 \mathrm{gh}$ & 119.9a \\
\hline Spaghetti 5 & 2.02 & 5.0 & $7.1 \mathrm{bcd}$ & $60.1 b c$ \\
\hline Spaghetti 6 & 1.88 & 4.9 & 6.5efg & 8.9gh \\
\hline Spaghetti 7 & 1.88 & 5.0 & 6.6def & $27.8 \mathrm{efg}$ \\
\hline Spaghetti 8 & 2.12 & 5.7 & $7.1 \mathrm{~cd}$ & $71.6 \mathrm{~b}$ \\
\hline Spaghetti 9 & 1.94 & 4.6 & 7.4abc & $16.2 \mathrm{fgh}$ \\
\hline Spaghetti 10 & 2.05 & 3.9 & $6.5 f g$ & $55.4 \mathrm{bcd}$ \\
\hline Spaghetti 11 & 1.97 & 5.3 & 6.9def & 13.6fgh \\
\hline Spaghetti 12 & 1.93 & 6.1 & $5.8 \mathrm{bcd}$ & $11.5 \mathrm{gh}$ \\
\hline Spaghetti 13 & 2.13 & 5.9 & 7.6ab & 14.0fgh \\
\hline Spaghetti 14 & 1.83 & 5.0 & 7.0cde & 34.6def \\
\hline Spaghetti 15 & 1.84 & 5.4 & $7.8 \mathrm{a}$ & $104.2 \mathrm{a}$ \\
\hline Spaghetti 16 & 1.92 & 5.9 & 6.6def & 9.3gh \\
\hline
\end{tabular}

Values with the same letter within the same column are not significantly different $(P<0.05)$.
In contrast to findings in literature (e.g. Cubadda et al., 2007; Dexter et al., 1981, 1983; Grant et al., 1993; Lamacchia et al., 2007; Novaro, D’Egidio, Mariani, \& Nardi, 1993; Zweifel et al., 2003), results from this study indicate that spaghettis 1 and 2, with low levels of polymerised protein and presumably dried under gentle conditions, had the highest cooking quality as revealed by a combination of lower cooking losses, higher firmness and lower surface stickiness than the other spaghetti samples.

\subsection{Swelling properties in relation to pasta cooking quality}

\subsubsection{General}

It is evident that protein polymerisation occurs both during pasta production and the subsequent cooking step. Also, proteins, polymerised to a variable degree, hinder starch swelling during pasta cooking. Thus, next to protein polymerisation, also starch swelling properties must be evaluated and related to the cooking quality. In addition, the impact of proteins on the swelling properties was determined using the reducing agent DTT.

\subsubsection{Swelling properties in the absence of shear stress}

The milled spaghettis 15 and 16 had higher SP (respectively 15.2 and $15.7 \mathrm{~g} / \mathrm{g}$ ) and carbohydrate leaching (respectively $29.9 \%$ and 31.5\%) during cooking than spaghettis 1 and 2 (SP 14.3 and $14.2 \mathrm{~g} / \mathrm{g}$, and carbohydrate leaching $26.6 \%$ and $28.0 \%$ respectively) as presented in Table 3 . The higher the SP, the more the pasta particles can swell, and the more the carbohydrates leach into the cooking water. Interestingly, the spaghettis of highest cooking quality (spaghettis 1 and 2) showed less swelling and carbohydrate leaching than the spaghettis of lower cooking quality (Table 3 ).

The use of DTT $(0.15 \% \mathrm{w} / \mathrm{v})$ increased the SP for all spaghettis (Table 3). Increasing the concentration of DTT had no additional effect on SP and leaching behaviour for any of the milled spaghettis. The effect of DTT on SP was more pronounced for spaghettis 1 and 2 than for spaghettis 15 and 16.

\subsubsection{Swelling properties in the presence of shear stress}

Table 4 lists the pasting temperatures, peak and end viscosities of milled dry spaghetti samples. Milled spaghettis 1 and 2 had higher RVA peak and end viscosities than did the ground spaghettis

Table 3

The effect of dithiothreitol (DTT, 0.15\%) on swelling power (SP, g/g) and carbohydrate leaching (\%) during cooking of semolina and milled dry spaghetti samples.

\begin{tabular}{|c|c|c|c|c|c|c|}
\hline & \multicolumn{3}{|l|}{$\mathrm{SP}(\mathrm{g} / \mathrm{g})$} & \multicolumn{3}{|c|}{ Carbohydrate leaching (\%) } \\
\hline & Control & + DTT & Difference & Control & + DTT & Difference \\
\hline Semolina 1 & $16.6 a$ & $21.1 \mathrm{ab}$ & 4.5 & $22.2 b$ & $21.4 \mathrm{~h}$ & 0.8 \\
\hline Semolina 2 & 15.6abcd & $20.5 \mathrm{abc}$ & 4.9 & $22.1 \mathrm{~b}$ & $21.8 \mathrm{gh}$ & 0.3 \\
\hline Semolina 3 & $16.4 \mathrm{ab}$ & $21.7 \mathrm{a}$ & 5.3 & $22.6 b$ & $23.6 \mathrm{fgh}$ & -1.0 \\
\hline Semolina 4 & $13.6 \mathrm{~d}$ & $16.1 d$ & 2.5 & $22.3 b$ & $21.4 \mathrm{~h}$ & 0.9 \\
\hline Semolina 5 & $16.6 a$ & 20.9ab & 4.3 & $22.4 \mathrm{~b}$ & $22.3 \mathrm{gh}$ & 0.1 \\
\hline Spaghetti 1 & $14.3 \mathrm{bcd}$ & $17.2 \mathrm{~d}$ & 2.9 & 26.6ab & 26.1defgh & 0.5 \\
\hline Spaghetti 2 & $14.2 \mathrm{~cd}$ & $16.6 d$ & 2.4 & $28.0 \mathrm{a}$ & $24.4 \mathrm{fgh}$ & 3.6 \\
\hline Spaghetti 3 & $15.4 \mathrm{abcd}$ & $16.1 \mathrm{~d}$ & 0.7 & $33.1 \mathrm{a}$ & 28.6abcde & 4.5 \\
\hline Spaghetti 4 & $14.2 \mathrm{~cd}$ & $16.6 \mathrm{~d}$ & 2.4 & 28.3ab & 28.4abcde & -0.1 \\
\hline Spaghetti 5 & $14.1 \mathrm{~cd}$ & $17.1 d$ & 3.0 & $29.4 \mathrm{ab}$ & $30.3 \mathrm{abc}$ & -0.9 \\
\hline Spaghetti 6 & 15.4abcd & 17.1bcd & 1.7 & $30.6 a$ & $31.8 \mathrm{ab}$ & -1.2 \\
\hline Spaghetti 7 & $13.9 \mathrm{~d}$ & $16.7 d$ & 2.8 & $28.7 \mathrm{ab}$ & 29.4abcd & -0.7 \\
\hline Spaghetti 8 & 14.7abcd & $18.2 \mathrm{bcd}$ & 3.5 & 29.9ab & $31.8 \mathrm{ab}$ & -1.9 \\
\hline Spaghetti 9 & 14.6abcd & $16.6 \mathrm{~d}$ & 2.0 & $28.4 \mathrm{ab}$ & 27.7bcdef & 0.7 \\
\hline Spaghetti 10 & 15.2abcd & $16.5 \mathrm{~d}$ & 1.3 & $34.4 \mathrm{a}$ & $30.5 \mathrm{abc}$ & 3.9 \\
\hline Spaghetti 11 & 14.8abcd & $16.4 \mathrm{~d}$ & 1.6 & $29.0 \mathrm{ab}$ & 26.4cdefg & 2.6 \\
\hline Spaghetti 12 & 15.3abcd & $17.0 \mathrm{~d}$ & 1.7 & $28.6 a b$ & 28.6abcde & 0 \\
\hline Spaghetti 13 & $16.1 \mathrm{abc}$ & $18.2 \mathrm{bcd}$ & 2.1 & $32.1 \mathrm{a}$ & $30.4 \mathrm{abc}$ & 1.7 \\
\hline Spaghetti 14 & $14.1 \mathrm{~cd}$ & $18.1 \mathrm{bcd}$ & 4.0 & $28.2 \mathrm{ab}$ & $33.1 \mathrm{a}$ & -4.9 \\
\hline Spaghetti 15 & $15.2 \mathrm{abc}$ & $16.6 \mathrm{~cd}$ & 1.4 & $29.9 \mathrm{ab}$ & 24.5cdefgh & 5.4 \\
\hline Spaghetti 16 & 15.7abcd & $16.6 \mathrm{~d}$ & 0.9 & $31.5 \mathrm{ab}$ & 23.3efgh & 8.2 \\
\hline
\end{tabular}

Means with the same letter within the same column are not significantly different $(P<0.05)$. 
Table 4

The effect of dithiothreitol (DTT, $0.15 \%$ ) on RVA pasting properties of semolina and milled dry spaghettis $(12.0 \% \mathrm{w} / \mathrm{v})$.

\begin{tabular}{|c|c|c|c|c|c|c|c|c|c|}
\hline & \multicolumn{3}{|c|}{ Pasting temperature $\left({ }^{\circ} \mathrm{C}\right)$} & \multicolumn{3}{|c|}{ Peak viscosity $(\mathrm{cP})$} & \multicolumn{3}{|c|}{ End viscosity $(\mathrm{cP})$} \\
\hline & Control & + DTT & Difference & Control & +DTT & Difference & Control & +DTT & Difference \\
\hline Semolina 1 & 81.3 & 82.0 & -0.7 & 3980 & 3755 & 225 & 4610 & 3890 & 720 \\
\hline Semolina 2 & 81.3 & 80.1 & 1.2 & 4270 & 3950 & 320 & 5340 & 4215 & 1125 \\
\hline Semolina 3 & 82.0 & 81.9 & 0.1 & 4605 & 4150 & 455 & 4735 & 3805 & 930 \\
\hline Semolina 4 & 82.9 & 81.9 & 1.0 & 5425 & 4830 & 595 & 5385 & 4415 & 970 \\
\hline Semolina 5 & 80.5 & 81.1 & -0.6 & 4520 & 4075 & 445 & 5125 & 4145 & 980 \\
\hline Spaghetti 1 & 65.5 & 64.0 & 1.5 & 4615 & 3110 & 1505 & 4925 & 3665 & 1260 \\
\hline Spaghetti 2 & 66.5 & 66.0 & 0.5 & 4775 & 2545 & 2230 & 5365 & 3185 & 2180 \\
\hline Spaghetti 3 & 65.0 & 64.6 & 0.5 & 4750 & 2140 & 2610 & 5185 & 2945 & 2240 \\
\hline Spaghetti 4 & 67.2 & 66.0 & 1.2 & 3260 & 2205 & 1055 & 4460 & 2860 & 1600 \\
\hline Spaghetti 5 & 65.0 & 66.1 & -1.1 & 4645 & 2190 & 2455 & 5045 & 2665 & 2380 \\
\hline Spaghetti 6 & 76.9 & 65.0 & 11.9 & 3565 & 4146 & -581 & 4030 & 3845 & 185 \\
\hline Spaghetti 7 & 67.2 & 63.6 & 3.7 & 3545 & 3701 & -156 & 4330 & 3798 & 532 \\
\hline Spaghetti 8 & 68.7 & 64.9 & 3.8 & 2720 & 2830 & -110 & 3660 & 3259 & 401 \\
\hline Spaghetti 9 & 67.0 & 66.0 & 1.0 & 4415 & 2815 & 1600 & 5005 & 3210 & 1795 \\
\hline Spaghetti 10 & 68.9 & 66.0 & 2.9 & 3210 & 2565 & 645 & 4495 & 3180 & 1315 \\
\hline Spaghetti 11 & 69.0 & 65.9 & 3.1 & 3210 & 2605 & 605 & 4225 & 3035 & 1190 \\
\hline Spaghetti 12 & 79.4 & 66.5 & 12.9 & 3510 & 3355 & 155 & 4374 & 3515 & 859 \\
\hline Spaghetti 13 & 67.5 & 67.0 & 0.5 & 3710 & 2345 & 1365 & 4770 & 2835 & 1935 \\
\hline Spaghetti 14 & 66.7 & 64.6 & 5.1 & 3860 & 3470 & 390 & 4600 & 3480 & 1120 \\
\hline Spaghetti 15 & 78.9 & 66.9 & 12.0 & 3475 & 3555 & -80 & 4735 & 3657 & 1078 \\
\hline Spaghetti 16 & 76.8 & 67.0 & 9.8 & 3615 & 2795 & 820 & 4780 & 3235 & 1545 \\
\hline
\end{tabular}

15 and 16. This means that spaghettis 1 and 2 must have rigid particles, which during swelling, resisted shear during the heating process before disintegrating. No correlation was found between the SP and the RVA peak viscosity. In addition, the high peak viscosity may also be related to the low content of starch damage. Damaged starch can absorb more water at room temperature and hence swells earlier than native starch (Karkalas, Tester, \& Morrison, 1992), which leads to lower peak viscosity and a lower pasting temperature (Güler, Köksel, \& Ng, 2002). Spaghettis 15 and 16 had the highest pasting temperatures, which means that the swelling of the starch containing particles was postponed, probably due to the more aggregated proteins during processing of these pastas (Table 4).

Addition of DTT decreased RVA pasting temperatures and viscosities for almost all samples. This means that a disulfide linked protein network exists and increases the particles' shear resistance. The effect of DTT on the shear resistance of particles was more pronounced for spaghettis 1 and 2. The effect of DTT on the pasting temperature was more pronounced for spaghettis 15 and 16 which in these cases may be attributed to the postponed particle swelling due to the existence of a protein network. It is remarkable that the peak viscosities and the SP of the spaghettis 1,2 and 15, 16 in the presence of DTT were quite similar (Table 3 and 4). This means that the starch properties of the starting raw materials for the commercial spaghettis are presumably similar. Thus, the different behaviour of the milled particles in TRIS- $\mathrm{HCl}$ buffer, as mentioned above, is mainly determined by the differences in protein properties.

The results indicate that, during cooking, the milled spaghettis 1 and 2 (the highest quality pastas) swell little and have the most shear resistant particles due to the protection by a protein network which, to a considerable degree, is formed during the cooking process itself. The SDSEP data and the gelatinisation temperatures of the dried pastas indicated that spaghettis 1 and 2 had been dried under gentle conditions. So, the protein network during cooking of the highest quality pastas (dried under gentle conditions) gives the particles more shear resistance than the network of the lowest quality spaghettis (dried under severe conditions) as the latter network lacked resilience. Addition of DTT during RVA analysis resulted in a protein network that no longer prevented the swelling of starch.

\section{Conclusion}

The results of this study indicate that a disulfide linked protein network exists in all spaghettis which provides shear resistance to particles and restricts starch swelling and subsequent leaching. An optimum in protein polymerisation during processing and/or cooking of spaghetti is critical for obtaining high quality pasta. When the proteins are polymerised too strongly during processing (in particularly during harsh drying conditions), they lack resilience to cope with starch swelling during cooking. This, in turn, results in more cooking losses and stickier spaghetti. This means that, in our view, too much protein polymerisation during processing is deleterious for spaghetti cooking quality. On the other hand, when the proteins are polymerised less during processing (in particularly during gentle drying), the polymerisation occurs mostly during cooking, and the proteins are more apt to follow the starch swelling resulting in higher quality pasta (less cooking losses and less sticky pasta). In conclusion, protein polymerisation is necessary during industrial drying to achieve high quality pasta, but the proteins must maintain enough resilience to cope with starch swelling during cooking. If not, the protein network cannot withstand the starch swelling, and, as a consequence, the final cooked pasta is stickier and more material is lost during cooking.

\section{Acknowledgements}

K. Brijs acknowledges the Industrial Research Fund (Katholieke Universiteit Leuven, Leuven, Belgium). This study was carried out in the framework of research project GOA/03/10 financed by the Research Fund K.U. Leuven. This study was performed as part of the K.U. Leuven Methusalem programme "Food for the future" (2007-2014).

\section{References}

AACC (1983). Approved methods of the American Association of Cereal Chemists, Methods 44-19 and 76-31 (10th ed.). St. Paul, MN, USA: AACC International. Abécassis, J., Abbou, R., Chaurand, M., Morel, M. H., \& Vernoux, P. (1994). Influence of extrusion conditions on extrusion speed, temperature, and pressure in the extruder and on pasta quality. Cereal Chemistry, 71(3), 247-253.

AOAC (1995). Official methods of analysis (16th ed.). Washington, DC: AOAC. 
Baiano, A., \& Del Nobile, M. A. (2006). Influence of drying temperature on the spaghetti cooking quality. Journal of Food Engineering, 76(3), 341-347.

Batey, I. L. (2007). Interpretation of RVA curves. In G. B. Crosbie \& A. S. Ross (Eds.) The RVA handbook (pp. 19-30). St. Paul, MN, USA: AACC International

Cornell, H. (2004). The functionality of wheat starch. In A.-C. E. Eliasson (Ed.), Starch in food: Structure, function and applications (pp. 211-240). Cambridge, UK: CRC Press Woodhead Publishing Ltd.

Cubadda, R. E., Carcea, M., Marconi, E., \& Trivisonno, M. C. (2007). Influence of gluten proteins and drying temperature on the cooking quality of durum wheat pasta. Cereal Chemistry, 84(1), 48-55.

Cunin, C., Handschin, S., Walther, P., \& Escher, F. (1995). Structural-changes of starch during cooking of durum-wheat pasta. Food Science and Technology Lebensmittel-Wissenschaft \& Technologie, 28(3), 323-328.

D’Egidio, M. G., Mariani, B. M., Nardi, S., \& Novaro, P. (1993). Viscoelastograph measures and total organic matter test: Suitability in evaluating textural characteristics of cooked pasta. Cereal Chemistry, 70, 67-72.

D’Egidio, M. G., Mariani, B. M., Nardi, S., Novaro, P., \& Cubadda, R. (1990). Chemical and technological variables and their relationships: A predictive equation for pasta cooking quality. Cereal Chemistry, 67, 275-281.

Delcour, J. A., Vansteelandt, J., Hythier, M. C., \& Abécassis, J. (2000a). Fractionation and reconstitution experiments provide insight into the role of starch gelatinization and pasting properties in pasta quality. Journal of Agricultura and Food Chemistry, 48(9), 3774-3778.

Delcour, J. A., Vansteelandt, J., Hythier, M. C., Abécassis, J., Sindic, M., \& Deroanne, C. (2000b). Fractionation and reconstitution experiments provide insight into the role of gluten and starch interactions in pasta quality. Journal of Agricultural and Food Chemistry, 48(9), 3767-3773.

Derycke, V., Veraverbeke, W. S., Vandeputte, G. E., De Man, W., Hoseney, R. C., \& Delcour, J. A. (2005). Impact of proteins on pasting and cooking properties of nonparboiled and parboiled rice. Cereal Chemistry, 82(4), 468-474.

Dexter, J. E., Dronzek, B. L., \& Matsuo, R. R. (1978). Scanning electron-microscopy of cooked spaghetti. Cereal Chemistry, 55(1), 23-30.

Dexter, J. E., Matsuo, R. R., \& Macgregor, A. W. (1985). Relationship of instrumenta assessment of spaghetti cooking quality to the type and the amount of material rinsed from cooked spaghetti. Journal of Cereal Science, 3(1), 39-53.

Dexter, J. E., Matsuo, R. R., \& Morgan, B. C. (1981). High-temperature drying - Effect on spaghetti properties. Journal of Food Science, 46(6), 1741-1746.

Dexter, J. E., Matsuo, R. R., \& Morgan, B. C. (1983). Spaghetti stickiness - Some factors influencing stickiness and relationship to other cooking quality characteristics. Journal of Food Science, 48(5), 1545-1551.

Dris, R., \& Niskanen, R. (1999). Quality changes of 'Lobo' apples during cold storage. International Symposium on Effect of Preharvest and Postharvest Factors on Storage of Fruit, 485, 125-131.

Dubois, M., Gilles, K. A., Hamilton, J. K., Rebers, P. A., \& Smith, F. (1956). Colorimetric method for determination of sugars and related substances. Analytical Chemistry, 28, 350-356.

Englyst, H. N., \& Cummings, J. H. (1984). Simplified method for the measurement of total non-starch polysaccharides by gas-liquid-chromatography of constituent sugars as alditol acetates. Analyst, 109, 937-942.

Gianibelli, M. C., Sissons, M. J., \& Batey, I. L. (2005). Effect of source and proportion of waxy starches on pasta cooking quality. Cereal Chemistry, 82(3), 321-327.

Grant, L. A., Dick, J. W., \& Shelton, D. R. (1993). Effects of drying temperature, starch damage, sprouting, and additives on spaghetti quality characteristics. Cereal Chemistry, 70(6), 676-684.

Güler, S., Köksel, H., \& Ng, P. K. W. (2002). Effects of industrial pasta drying temperatures on starch properties and pasta quality. Food Research International, 35(5), 421-427.

Karkalas, J., Tester, R. F., \& Morrison, W. R. (1992). Properties of damaged starch granules. I. Comparison of a micromethod for the enzymatic determination of damaged starch with the standard AACC and Farrand methods. Journal of Cereal Science, 16, 237-251.

Lagrain, B., Brijs, K., Veraverbeke, W. S., \& Delcour, J. A. (2005). The impact of heating and cooling on the physico-chemical properties of wheat gluten-water suspensions. Journal of Cereal Science, 42(3), 327-333.

Lagrain, B., Thewissen, B. G., Brijs, K., \& Delcour, J. A. (2008). Mechanism of gliadinglutenin cross-linking during hydrothermal treatment. Food Chemistry, 107(2), 753-760.

Lamacchia, C., Di Luccia, A., Baiano, A., Gambacorta, G., la Gatta, B., Pati, S., et al. (2007). Changes in pasta proteins induced by drying cycles and their relationship to cooking behaviour. Journal of Cereal Science, 46(1), 58-63.

Lintas, C., \& D'Appolonia, B. L. (1973). Effect of spaghetti processing on semolina carbohydrates. Cereal Chemistry, 50(5), 563-570.

Morrison, W. R., Tester, R. F., \& Gidley, M. J. (1994). Properties of damaged starch granules. 2. Crystallinity, molecular order and gelatinization of ball-milled starches. Journal of Cereal Science, 19(3), 209-217.

Novaro, P., D’Egidio, M. G., Mariani, B. M., \& Nardi, S. (1993). Combined effect of protein-content and high-temperature drying systems on pasta cooking quality. Cereal Chemistry, 70(6), 716-719.

Oak, M. D., Sissons, M., Egan, N., Tamhankar, S. A., Rao, V. S., \& Bhosale, S. B. (2006) Relationship between gluten strength and pasta firmness in Indian durum wheats. International Journal of Food Science and Technology, 41(5), 538-544.

Petitot, M., Brossard, C., Barron, C., Larré, C., Morel, M.-H., \& Micard, V. (2009). Modification of pasta structure induced by high drying temperatures. Effects on the in vitro digestibility of protein and starch fractions and the potential allergenicity of protein hydrolysates. Food Chemistry, 116(2), 401-412.

Pollini, C. M. (1996). THT technology in the modern industrial pasta drying process. In J. E. Kruger, R. B. Matsuo, \& J. W. Dick (Eds.), Pasta and Noodle technology (pp. 59-74).

Resmini, P., \& Pagani, M. A. (1983). Ultrastructure studies of pasta - A review. Food Microstructure, 2(1), 1-12.

Schofield, J. D., Bottomley, R. C., Timms, M. F., \& Booth, M. R. (1983). The effect of heat on wheat gluten and the involvement of sulphydryl-disulfide interchange reactions. Journal of Cereal Science, 1, 241-253.

Sissons, M. J., Ames, N. P., Hare, R. A., \& Clarke, J. M. (2005). Relationship between glutenin subunit composition and gluten strength measurements in durum wheat. Journal of the Science of Food and Agriculture, 85(14), 2445-2452.

Troccoli, A., Borrelli, G. M., De Vita, P., Fares, C., \& Di Fonzo, N. (2000). Durum wheat quality: A multidisciplinary concept. Journal of Cereal Science, 32(2), 99-113.

Vansteelandt, J., \& Delcour, J. A. (1998). Physical behavior of durum wheat starch (Triticum durum) during industrial pasta processing. Journal of Agricultural and Food Chemistry, 46(7), 2499-2503.

Veraverbeke, W. S., \& Delcour, J. A. (2002). Wheat protein composition and properties of wheat glutenin in relation to bread making functionality. Critical Reviews in Food Science and Nutrition, 42(3), 179-208.

Veraverbeke, W. S., Larroque, O. R., Bekes, F., \& Delcour, J. A. (2000). In vitro polymerization of wheat glutenin subunits with inorganic oxidizing agents. I. Comparison of single-step and stepwise oxidations of high molecular weight glutenin subunits. Cereal Chemistry, 77(5), 582-588.

Wood, J. A., Batey, I. L., Hare, R. A., \& Sissons, M. J. (2001). A comparison of Australian and imported spaghetti. Food Australia, 53(8), 349-354.

Yue, P., Rayas-Duarte, P., \& Elias, E. (1999). Effect of drying temperature on physicochemical properties of starch isolated from pasta. Cereal Chemistry, 76(4), 541-547.

Zweifel, C., Conde-Petit, B., \& Escher, F. (2000). Thermal modifications of starch during high-temperature drying of pasta. Cereal Chemistry, 77(5), 645-651.

Zweifel, C., Handschin, S., Escher, F., \& Conde-Petit, B. (2003). Influence of hightemperature drying on structural and textural properties of durum wheat pasta. Cereal Chemistry, 80(2), 159-167. 